on the anaesthesia and analgesia principles outlined in the recently published PROSPECT (PROcedure SPECific Postoperative Pain ManagemenT) guideline for Hallux Valgus repair surgery. ${ }^{1}$

Methods We performed a retrospective audit for patients who underwent forefoot surgery between $01 / 07 / 19$ to $31 / 12 / 19$. The data was collated from the Digital Health Records database, analysed in Microsoft Excel and presented at clinical governance meeting

Results A total of 102 patients underwent forefoot surgeries. Out of them, 68 patients had peripheral nerve blocks (PNBs) only, 30 had general anaesthetic alone or in combination with PNB or local anaesthetic infiltration (LAI) and 4 had only spinal anaesthetic. Ankle block was the most commonly performed PNB. Only 5\% of patients received systemic paracetamol + nonsteroidal anti-inflammatory drugs (NSAIDs) and $26 \%$ received intraoperative dexamethasone. Discharge prescription were missing for $22 \%$ of the patients. Of those retrievable, $89 \%$ included an opioid to take home.

Conclusions As recommended in the guideline, the ankle block was PNB of choice. The majority of those who did not have an ankle block, had a popliteal sciatic nerve block and saphenous nerve bock or LAI. However, there is scope of improvement in the use of intraoperative multimodal analgesia with paracetamol, NSAIDs and dexamethasone and appropriate discharge prescription for effective postoperative pain management.

\section{CONTINUOUS SUPRACLAVICULAR BRACHIAL PLEXUS BLOCK FOR REPLANTATION IN THE UPPER EXTREMITY - A CASE REPORT}

M Branco, AC Martins*, P Freire, M Chedas. Centro Hospitalar de Lisboa Ocidental, Lisboa, Portugal

\subsection{6/rapm-2021-ESRA. 165}

Background and Aims Continuous brachial plexus block (CBPB) with local anaesthetic is useful for long surgical operations on upper extremity. CBPC improve tissue perfusion after replantation surgery of the extremity by decreasing vasospasm, relieving pain, and promoting collateral circulation. In reconstructive surgery is particularly important because sympathetic blockade of the vessels provides increased blood flow to the injured extremity, which increases the success rate of the surgery. ${ }^{1,2}$

Methods We present a case of a 51-year-old man, ASA 2, who had combined anaesthetic technique with continuous supraclavicular block of the brachial plexus to prevent postoperative pain and maintain extended vasodilatation.

The procedure was successfully completed under combined anesthesia.

Results In the reported case, CBPB was effective providing the best analgesia during the postoperative period and preventing the development of vasospasm in the digital arteries of the reimplanted digit and improving graft survival. The patient had a satisfactory evolution during the postoperative period, with adequate analgesia. No complications were reported.

Conclusions Microsurgical operation of the hand is a common procedure of reconstructive surgery. $\mathrm{CPPB}$ offers numerous advantages in terms of the best graft perfusion and was found to be effective in both sympathetic blockade and postoperative pain management. ${ }^{1-4}$

\section{THE EFFICACY OF MODIFIED THORACOABDOMINAL NERVES BLOCK THROUGH PERICHONDRIAL APPROACH: A PROSPECTIVE OBSERVATIONAL STUDY AND A CADAVERIC EVALUATION}

N Tanaka*, T Suzuka, Y Kadoya, M Kawaguchi. Nara Medical University, Kashihara, Nara, Japan

\subsection{6/rapm-2021-ESRA.166}

Background and Aims Modified thoracoabdominal nerves block through perichondrial approach (M-TAPA) was first described as a peripheral nerve block by Tulgar in 2019, which provides an analgesic effective range in Th7-11 with a single puncture per side $_{1}$. The efficacy and effective duration of the M-TAPA has been reported in several case reports; however its effects require further examination.

Methods With an IRB approval (No.2700) and registration (UMIN Clinical Trials Registry: UMIN000041137), 10 adult female patients scheduled for an open radical hysterectomy with vertical incision or laparotomy with a midline incision from under the xiphoid process to the symphysis pubis were enrolled. The primary outcome was the number of anesthetized dermatomes at 2 and $24 \mathrm{~h}$ postoperatively. Secondary outcomes included the numerical rating scale scores and the total amount of fentanyl used. Cadaveric evaluation was performed to assess the spread of the dye.

Results Patient characteristics are shown in table 1 . The median number (interquartile range) of anesthetized
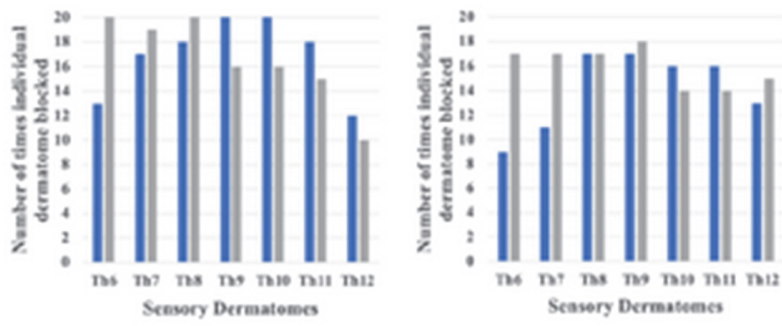

Abstract 166 Figure 1

Abstract 166 Table 1 Patient characteristics

\begin{tabular}{|c|c|}
\hline & All paticnts $(n-10)$ \\
\hline Age (years), median (IQR) & $50.4(43.5-58.5)$ \\
\hline ASA grade (1/2) & 37 \\
\hline Height (cm), mean (SD) & $156 \pm 5$ \\
\hline Wcight (kg), mean (SD) & $60 \pm 10$ \\
\hline Duration of surgery (min), median (IQR) & $241(159-260)$ \\
\hline Duration of ancsthesia (min), median (lQR) & $298(193-322)$ \\
\hline Intraopcrative fentanyl use ( $\mu \mathrm{g} \mathrm{kg}$ ), molian (IQR) & $7.1(5.7-9.5)$ \\
\hline $\begin{array}{l}\text { Time-weighted avcrage of remifentanil use } \\
\text { ( } \mu \mathrm{g} \mathrm{kg} \text { min), median ( } \mathrm{QQR} \text { ) }\end{array}$ & $0.18(0.15-0.22)$ \\
\hline Blood loss (mL), median (LQR) & $728(448-770)$ \\
\hline Urine cutput (mL), median (IQR) & $205(155-270)$ \\
\hline Total Input (mL), modian (lQR) & $3000(2300-3383)$ \\
\hline Pre-oprrative Albumin (mg dL), mean (SD) & $4.3 \pm 0.2$ \\
\hline \multicolumn{2}{|l|}{ Type of surgsty } \\
\hline $\mathrm{ATH}+\mathrm{BSO}+\mathrm{PLA}+\mathrm{PALA}+\mathrm{OMX}$ & 4 \\
\hline $\mathrm{ATH}+\mathrm{BSO}+\mathrm{PLA}$ & 3 \\
\hline $\mathrm{ATH}+\mathrm{BSO} \cdot \mathrm{OMX}$ & 2 \\
\hline BSO OMX & 1 \\
\hline
\end{tabular}

